\title{
Effect of self-employment on the sub-health status and chronic disease of rural migrants in China
}

\author{
Jian Zhou, Qiushi Wu and Zicheng Wang * (])
}

\begin{abstract}
Background: Rural migrants usually suffer from major disease risks, but little attention had been paid toward the relationship between self-employment behavior and health status of rural migrants in China. Present study aims to explore the causal effect of self-employment behavior on rural migrants' sub-health status and chronic disease. Two research questions are addressed: does self-employment status affect the sub-health status and chronic disease of rural migrants? What is potential mechanism that links self-employment behavior and health status among rural migrants in China?
\end{abstract}

Methods: The dataset from the 2017 National Migrants Population Dynamic Monitoring Survey (NMPDMS-2017) was used to explore the causal effect. Logit regression was performed for the baseline estimation, and linear probability model with instrument variable estimation (IV-LPM) was applied to correct the endogeneity of self-employment. Additionally, logit regression was conducted to explore the transmission channel.

Results: Self-employed migrants were more susceptible to sub-health status and chronic disease, even when correcting for endogeneity. Moreover, self-employed migrants were less likely to enroll in social health insurance than their wage-employed counterparts in urban destinations.

Conclusion: Self-employed migrants were more likely to suffer from sub-health status and chronic disease; thus, their self-employment behavior exerted a harmful effect on rural migrants' health. Social health insurance may serve as a transmission channel linking self-employment and rural migrants' health status. That is, self-employed migrants were less prone to participate in an urban health insurance program, a situation which leaded to insufficient health service to maintain health.

Keywords: Self-employment, Sub-health status, Chronic disease, Rural migrants, Social health insurance program

\section{Background}

Since 1978, China has experienced rapid and unprecedented urbanization in which millions of migrants move from rural to urban areas. Rural migrants have become an important segment of industrial workers and have made great contributions to urban development $[1,2]$.

*Correspondence: twzc976@jnu.edu.cn

School of Public Administration, Jinan University, 601 Huangpu Blvd,

Tianhe District, Guangzhou 510632, Guangdong Province, China
Nevertheless, rural migrants often work in the secondary urban labor market, which involves lower income, unstable jobs, longer work hours, and the lack of occupational health protection $[3,4]$. Such situation not only affects the socio-economic status of rural migrants in urban destinations, but may also produce negative effects on rural migrants' health $[4,5]$. Previous studies have revealed that rural migrants usually suffer from major disease risks, especially occupational diseases, chronic illnesses, and sexually transmitted diseases $[6,7]$. 
To improve their socio-economic status, a large proportion of rural migrants choose to engage in selfemployment [8], which is defined as proprietors of privately or individually-owned businesses with no hired labor following the Social Insurance Law of the People's Republic of China in 2011. Self-employment is often characterized by high work autonomy, flexibility and skill utilization as well as high income $[9,10]$. Nevertheless, self-employment often involves considerable uncertainty in business activities (such as investment risk, market fluctuation, and irregular working hours), which may cause unhealthy behaviors [11]. Thus, a rich array of literature has explored the effect of self-employment on health, but no consensus has been reached in empirical studies. The job demand-control model posits that job demand increases the work-related stress of the selfemployed, whereas their higher job control reduces it. That is, job control can weaken the negative relationship between self-employment and work-related stress; thus, the self-employed are healthier than their wage-employed counterparts [12]. In addition, the independence, autonomy, and high compensation from self-employment may induce life satisfaction [13, 14]. A growing body of evidence confirmed that self-employment status had a positive impact on health status [12, 15, 16]. Furthermore, self-employed individuals experienced better health than wage-employed employees [17-19].

A few studies also revealed the contrary conclusion that self-employment was negatively related with health status $[20,21]$. Self-employed people were often confronted with unanticipated demand shocks, a circumstance that subjected them to high workload and volatile earning flows, which, in turn, had been implicated as causes of stress. Work-related stress not only deteriorated performance at work but may also impair the health status of the self-employed [22, 23]. Work-related stress was also associated with unhealthy behaviors such as smoking and drinking, and these habits may further deteriorate workers' health status [24, 25]. In addition, self-employment only exerted a positive effect on perceived health, but had a negative effect on workers' objective health status [26].

The potential causes of those inconsistent conclusions may be due to endogeneity, which posited that selfemployment and health were mutually influenced. Giandrea, Cahill and Quinn [27] found that poor health status had negatively impact on individual self-employment decision. However, the existing studies did not address this endogeneity [12, 15], and the instrumental variable approach should be applied to present an unbiased estimation. Furthermore, the mechanism linking selfemployment status and health was underexplored.

Previous research in China mainly focused on the determinants of self-employment decision, such as the institutional environment and social networks [28, 29]. Little attention had been paid toward the relationship between self-employment behavior and health status of rural migrants, and discussion on the transmission channel linking self-employment and rural migrants' health remains scant.

However, China currently faces serious health challenges. Sub-health status has become a new public health issue in China. It refers to an intermediate health state between health and disease, and it is characterized by a decline in vitality, physiological function, and capacity for adaption; this status is regarded as a subclinical, reversible stage of chronic disease [30,31]. The number of people who reported suboptimal health status, that is, poor health in the absence of a diagnosable condition, has increased in China in recent years. Thus, studies on improving the intervention and prognosis for sub-health status have become increasingly important. According to the blue book of health management, chronic diseases numbered approximately 300 million in 2018 [32]. In the "Thirteenth Five-Year Plan," chronic disease health management has been upgraded to a national strategic height. Thus, chronic diseases have become an important public health issue and have attracted increasing attention from scholars and policy makers. Hypertension and diabetes were two of the most common chronic diseases according to Tilov, Semerdzhieva, Bakova, Tornyova and Stoyanov [33] and DeVol et al. [29]. Healthy China Initiative (2019-2030) showed that 270 million people had hypertension and more than 97 million had diabetes in China. Therefore, hypertension and diabetes were chosen as proxies for chronic disease in this study. As a unique group, little attention has been given to the health status (including chronic diseases and sub-health status) of selfemployed rural migrants in China. Therefore, this study focused on the effect of self-employment on the health status of rural migrants, including two sets of health indicators, namely, sub-health status and chronic disease.

This study addressed these gaps by exploring two issues: does self-employment status affect the sub-health status and chronic disease of rural migrants? If so, what is the potential mechanism that links self-employment behavior and health status?

This research contributed to the literature in three distinct ways. First, this study was unique, given its focus on internal migrant groups. A comprehensive database in China was used to explore the direct association between self-employment behavior and sub-health status as well as the chronic disease of rural migrants. Second, this research applied linear probability model with instrument variable to correct the potential endogeneity of self-employment in order to identify the precise causal effects of self-employment behavior on health status. By 
comparison, previous studies merely explored the correlation by using multiple non-linear regression analysis. Third, the potential transmission channels linking selfemployment status and health were discussed in the context of China by estimating the effect of self-employment on social health insurance.

\section{Methods} Study design

Data from the 2017 National Migrants Population Dynamic Monitoring Survey (NMPDMS-2017) was analyzed in this work. In this survey, the stratified multistage random sampling method with the probability proportional to size approach was employed to extract sampling points from 31 provinces and the Xinjiang Production and Construction Corps (XPCC) in China. These samples included internal migrants aged 15-69years who did not have the local "household registration system (Hukou)," an institution with the power to restrict population mobility and access to local public benefit for rural population, and have been living in destination cities for more than 1 month. The NMPDMS-2017 survey had two features that made it particularly suitable for our research. First, the sample size was large, which contained 169,989 rural migrants. Second, it collected a wide variety of data related to the demography, employment traits, and health status among rural migrants.

As this study aimed to investigate the effect of selfemployment on the health status of rural migrants including the self-employed and wage workers that had rural household registrations, participants who were employers, temporary workers, or unemployed and those without rural household registrations were excluded. According to the definition of migrants and after dropping missing data, we obtained 114,675 valid samples, including 39,937 self-employed and 74,738 wage-employed rural migrants.

\section{Self-employment assessment}

The definition of self-employment varied slightly across countries. A rich array of studies was conducted on the basis of official data sets for which the definition of selfemployment is similar to that adopted by the International Labour Organization (ILO) [34]. According to the ILO, self-employment comprised three specific groups: self-employed workers with employees (employers), selfemployed workers without employees (own-account workers), and members of producers' cooperatives and contributing family workers. Following ILO, the Social Insurance Law of the People's Republic of China in 2011 regarded self-employment as a part of flexible employment and defined the self-employed as proprietors of privately or individually owned businesses with no hired labor.

Thus, rural migrants who ran privately or individually owned businesses with no hired labor were identified as the self-employed in this work. The item for employment status was used to define self-employment, such that participants who ran their own businesses without employees were coded as 1 , and as 0 if otherwise.

\section{Health measure}

Two sets of health indicators, sub-health status and chronic disease, were applied to measure the health status of rural migrants.

Sub-health status in the study was assessed through the question "How is your health?" Responses were coded as 1 if the participant reported his/her health status between health and illness, and as 0 if otherwise. In addition, the definition of chronic disease was derived from the item "Have you been diagnosed with hypertension or diabetes?" Participants who suffered from hypertension or diabetes were coded as 1 , and as 0 if otherwise.

\section{Potential covariates}

In line with Rietveld, Kippersluis, and Thurik [35] and Wong et al. [36], the potential covariates in this work were categorized as socioeconomic characteristics (i.e., gender, age, age-squared, education attainment, income, and marital status), work characteristics, and migration traits (i.e., those who migrated with their children and those who migrated with their spouse). Descriptions of the measures were presented in Table 1.

\section{Instrumental variables}

As discussed before, the health status of rural migrants might affect their self-employment decision [37], that is, those with poor health face more difficulty in being selfemployed, which have to bear higher levels of stress and working hours [38]. In order to address the bias resulting from this simultaneity, the study employed linear probability model with instrument variable estimation as our empirical approach.

We aggregated individual-level self-employment at the provincial level with sample weights to construct provincial self-employment rate as our instrument variable. We would define the measure of the provincial self-employment rate and discuss the rationale for this choice in next section.

\section{Model strategy}

Since our main dependent variable was binary health indicators, the results of logit model were more accurate comparing with linear probability model, a binary logit model was applied to explore the effect of self-employment 
Table 1 Operationalization of variables

\begin{tabular}{|c|c|c|}
\hline Variable & Description & Items \\
\hline \multicolumn{3}{|l|}{ Dependent variables } \\
\hline Chronic disease & $\begin{array}{l}=1 \text { if one suffer from Hypertension or Diabetes; }=0 \\
\text { otherwise; }\end{array}$ & $\begin{array}{l}\text { Question: Do you suffer from Hypertension or Diabetes } \\
\text { diagnosed by your doctor? }\end{array}$ \\
\hline Sub-health status & $=1$ if one is in sub-health status; $=0$ otherwise; & Question: How is your health? \\
\hline \multicolumn{3}{|l|}{ Focal variable } \\
\hline Self-employment & $=1$ if one is self-employed; $=0$ if wage-employed; & Question: What is your employment status? \\
\hline \multicolumn{3}{|l|}{ Control variables } \\
\hline \multicolumn{3}{|c|}{ Socio-economic characteristics } \\
\hline Gender & $=1$ if male; $=0$ if female; & Question: What is your gender? \\
\hline Age & $15 \leq$ age $\leq 96$ & Question: Year of birth \\
\hline Age^2 & Age squared; & Question: Year of birth \\
\hline \multicolumn{3}{|l|}{ Educational attainment } \\
\hline Primary school or below & $=1$ if education year $\leq 6,=0$ otherwise & Question: What's your education level? \\
\hline Junior high school & $=1$ if $6<$ education year $\leq 9,=0$ otherwise & Question: What's your education level? \\
\hline Senior high school & $=1$ if $9<$ education year $\leq 12,=0$ otherwise & Question: What's your education level? \\
\hline College or above & $=1$ if education year $>12,=0$ otherwise & Question: What's your education level? \\
\hline Income (monthly), Y & Net income for last month at time of interview & Question: How much was your salary last month? \\
\hline Marital status & $=1$ if married; $=0$ if unmarried; & Question: What's your marital status? \\
\hline \multicolumn{3}{|l|}{ Work characteristic } \\
\hline Construction industry & $=1$ if one works in construction industry; $=0$ otherwise; & Question: What's do you work in industry? \\
\hline Service industry & $=1$ if one works in service industry $=0$ otherwise; & Question: What's do you work in industry? \\
\hline Other industry & $\begin{array}{l}=1 \text { if one works in other industry; }=0 \text { works in construc- } \\
\text { tion or service industry; }\end{array}$ & Question: What's do you work in industry? \\
\hline \multicolumn{3}{|l|}{ Migration traits } \\
\hline Children migration & $=1$ if children migrates together only; $=0$ otherwise & Question: What is your relationship with the interviewee? \\
\hline Couple migration & $=1$ if couple migrates together only; $=0$ otherwise & Question: What is your relationship with the interviewee? \\
\hline
\end{tabular}

behavior on rural migrants' health status. The following reduced form equation serves as the benchmark model:

$$
H_{i}=\alpha+\phi \operatorname{self}_{i}+\beta x_{i}+\varepsilon_{i},
$$

Where $H_{i}$ measured two sets of health indicators, namely chronic disease (equal to 1 if migrants suffered from hypertension or diabetes, and 0 if otherwise) and sub-health status (equal to 1 if migrants suffered from sub-health status, and 0 if otherwise). Focal variable self $_{i}$ was a dummy variable representing whether the rural migrants were self-employed or not. $x_{i}$ controlled for various socio-demographic characteristics, work characteristics and migration-related traits that may affect health status. Finally, $\varepsilon_{i}$ captured the random error.

The effect of self-employment on health status may be biased because of the reverse causality in the logit estimation, and self-employment in Eq. (1) was a dummy variable, thus IV-LPM may be appropriate in the study. ${ }^{1}$

\footnotetext{
${ }^{1}$ Additionally, in order to compare the results of IV-LPM, we also estimated linear probability model (LPM) in Table 4.
}

$$
\operatorname{self}_{i}=\delta_{0}+\delta_{1} x_{i}^{\prime}+\delta_{2} Z_{i}^{\prime}+v_{i}
$$

Where $\operatorname{self}_{i}$ was a dummy variable for self-employed status, $x_{i}^{\prime}$ incorporated the control variables, $v_{i}$ was the random error, and $Z_{i}^{\prime}$ represented the instrument variable.

A valid instrument of self-employment should meet two criteria: it must be strongly related with the selfemployed and cannot be associated with $v_{i}$. We chose provincial self-employment rate as the equivalent instrument, which was calculated from the NMPDMS-2017 survey. Since the NMPDMS-2017 survey obtained samples using a stratified multistage random sampling method with the probability proportional to size approach, we applied individual standardized weights $\left(\omega_{i}\right)$ to each sample to improve the accuracy of the estimation when calculating provincial self-employment rate. The measurement of provincial self-employment rate was as followed. Firstly, we calculated the sum of self-employed individuals in a province by weighting, $S_{j}=\sum \operatorname{self}_{i} \omega_{i}(\operatorname{self}=0,1, j=1, \ldots, 32)$; Secondly, we calculated the sum of total samples in a province by weighting, $P_{j}=\sum I \omega_{i}(I=1)$; Finally, the provincial self-employment 
rate equaled the sum of the weight of the number of the self-employed $\left(S_{j}\right)$ dividing by the weight of total samples in a province $\left(P_{j}\right), Z_{j}=\frac{S_{j}}{P_{j}}$.

\section{The choice of the instrumental variables}

The potential reasons for instrument selection were as follows. Provincial self-employment rate represented the vitality of innovation and entrepreneurship in urban destinations and had a direct impact on individuals' selfemployment behaviors. Most of the regional policies in China focused on supporting entrepreneurs, which directly affected individual self-employment choice [39-41]. That is, the high regional self-employment rate implied a better entrepreneurship environment, a feature that plays an important role in entrepreneurial orientation $[41,42]$. As expected, provincial self-employment rate has been positively related to the self-employment behavior in the result of the first stage of IV-LPM. In Table 6 in Appendix, the F statistic in the first stage of the sub-health status model and the chronic disease model also indicated that the instrument variable was strong $(\mathrm{F}>10)$. We respectively reported Anderson canon. Corr. LM statistic and Cragg-Donald Wald F statistics. The former was jointly significant at the $1 \%$ level, which passed unidentified test, and the latter were more than the Stock-Yogo weak ID test critical values at the 10\% maximal IV size, which also rejected the null hypothesis of weak IV. Therefore, the instrument variable was valid for correcting endogeneity in this study.

In addition, provincial self-employment rate had no direct influence on the health of rural migrants at the individual level according to the calculation mode. Overall, the instrument variable was orthorhombic with the self-employment of rural migrants in urban destinations and was unrelated to the error term in the main regression model. Consequently, we selected the provincial self-employment rate as our instrument variable.

Giandrea, Cahill and Quinn [37] found that poor health status had negatively impact on individual self-employment decision. Given their finding, the OLS estimates in this study were downward bias. After correcting the bias by using IV-LPM regression, our IV estimates indicated that our findings were in accord with Giandrea, Cahill and Quinn [37] reversed causality story.

\section{Results}

\section{Descriptive statistics}

The resulting descriptive statistics are shown in Table 2 . Self-employed rural migrants accounted for 34.83\% $(n=39,937)$ of total observations. 15.33\% $(n=17,085)$ and $7.39 \%(n=8474)$ of the rural migrants experienced sub-health status and chronic disease, respectively. Nearly half of the participants were male migrants, and the average age was approximately 35 years old. Most of the rural migrants completed the nine-year compulsory education, and $32.54 \%$ of them also achieved educational attainments over senior high school.

The baseline characteristics by employment status revealed that the self-employed migrants suffered more health risks than their wage-employed counterparts (subhealth status: $15.68 \%$ vs. $15.14 \%$; chronic disease: $8.46 \%$ vs. $6.82 \%)$. Male self-employed migrants outnumbered female self-employed migrants $(57.80 \%$ vs. $42.20 \%)$, and the average age of the self-employed migrants was higher than that of wage-employed ones (37.59 vs. 34.19). Moreover, the wage-employed had higher education levels than self-employed counterparts (primary school or below: $17.96 \%$ vs. $22.23 \%$; junior high school: $44.51 \%$ vs. $54.55 \%$; senior high school: $22.34 \%$ vs. $18.47 \%$; college or above: $15.19 \%$ vs. $4.75 \%)$. Moreover, service industry was the most important industry for self-employed migrants, where $76.50 \%$ of them worked in; and the self-employed had higher incomes than the wage-employed (RMB 4108.99 vs. RMB 3850.94). Additionally, self-employed migrants had a higher likelihood of migrating with their family. Among those workers, $76.24 \%$ migrated with their children, and $85.63 \%$ migrated with their spouse.

\section{Baseline estimation}

Two logistic regressions were applied to explore the effect of self-employment on rural migrants' health status. Sub-health status and chronic disease were considered distinct dependent variables. The results are shown in Table 3.

In the sub-health status model, the effect of the key variable was significantly positive, which indicated that the self-employment had a negative impact on the subhealth status of rural migrants $(\beta=0.0377 ; 95 \% \mathrm{CI}$ : $-0.0044,0.0798)$. That is, self-employed migrants were more likely to suffer from sub-health status than their employed counterparts in China. Meanwhile, being married $(\beta=0.2514,95 \%$ CI: $0.1570,0.3458)$ increased the likelihood of suffering from sub-health status. By contrast, gender $(\beta=-0.1508,95 \%$ CI: -0.1913 , -0.1103 ), educational attainment (junior high school: $\beta=-0.1764,95 \%$ CI: $-0.2271,-0.1257$; senior high school: $\beta=-0.1826,95 \%$ CI: $-0.2471,-0.1181$; college or above: $\beta=-0.1708,95 \% \mathrm{CI}:-0.2545,-0.0872)$ and income $(\beta=-0.00004,95 \% \mathrm{CI}:-0.00005,-0.00003)$ had a negative impact on the sub-health status of rural migrants. Industry factor had a similar result, such that rural migrants working in construction and service industries were less likely to suffer from sub-health status than their counterparts working in other industries (construction industry: $\beta=-0.0690,95 \% \mathrm{CI}:-0.1404$, 0.0024; service industry: $\beta=-0.0616,95 \%$ CI: -0.1285 , 
Table 2 Descriptive statistics of study participants according to employment status. (NMPDMS-2017)

\begin{tabular}{|c|c|c|c|c|}
\hline & $\begin{array}{l}\text { Full sample } \\
\mathrm{N}(\%)\end{array}$ & $\begin{array}{l}\text { Self-employed } \\
\mathrm{N}(\%)\end{array}$ & $\begin{array}{l}\text { Wage-employed } \\
\mathrm{N}(\%)\end{array}$ & $P$-value \\
\hline \multicolumn{5}{|l|}{ Health status } \\
\hline \multicolumn{5}{|l|}{ Sub-health status } \\
\hline Sub-healthy, n (\%) & $17,085(15.33)$ & $6136(15.68)$ & $10,949(15.14)$ & \multirow[t]{2}{*}{0.018} \\
\hline Healthy, n (\%) & $94,339(84.67)$ & $32,992(84.32)$ & $61,347(84.86)$ & \\
\hline \multicolumn{5}{|l|}{ Chronic disease } \\
\hline Have Hypertension or Diabetes, n (\%) & $8474(7.39)$ & $3378(8.46)$ & $5096(6.82)$ & \multirow[t]{2}{*}{0.000} \\
\hline Without Hypertension or Diabetes, n (\%) & $106,201(92.61)$ & $36,559(91.54)$ & $69,642(93.18)$ & \\
\hline \multicolumn{5}{|l|}{ Socio-economic characteristics } \\
\hline \multicolumn{5}{|l|}{ Gender } \\
\hline Male, n (\%) & $57,279(49.95)$ & $23,085(57.80)$ & $34,194(45.75)$ & \multirow[t]{2}{*}{0.000} \\
\hline Female, n (\%) & $57,396(50.05)$ & $16,852(42.20)$ & $40,544(54.25)$ & \\
\hline Age mean $\pm S D$ & $35.372 \pm 10.884$ & $37.591 \pm 9.533$ & $34.187 \pm 11.366$ & 0.000 \\
\hline Age $\wedge 2$, mean $\pm S D$ & $35.372 \pm 10.884$ & $37.591 \pm 9.533$ & $34.187 \pm 11.366$ & 0.000 \\
\hline \multicolumn{5}{|l|}{ Education attainment } \\
\hline Primary school or below, n (\%) & $22,301(19.45)$ & $8878(22.23)$ & $13,423(17.96)$ & 0.000 \\
\hline Junior high school, n (\%) & $55,056(48.01)$ & $21,787(54.55)$ & $33,269(44.51)$ & 0.000 \\
\hline Senior high school, n (\%) & $24,070(20.99)$ & $7376(18.47)$ & $16,694(22.34)$ & 0.000 \\
\hline College or above, n (\%) & $13,248(11.55)$ & $1896(4.75)$ & $11,352(15.19)$ & 0.000 \\
\hline \multicolumn{5}{|l|}{ Marital status } \\
\hline Married, n (\%) & $96,687(84.31)$ & $37,303(93.40)$ & $59,384(79.46)$ & \multirow[t]{2}{*}{0.000} \\
\hline Unmarried, n (\%) & $17,988(15.69)$ & $2634(6.60)$ & $15,354(20.54)$ & \\
\hline Income (monthly), mean \pm SD & $3962.79 \pm 2858.13$ & $4108.99 \pm 3461.81$ & $3850.94 \pm 2284.99$ & 0.000 \\
\hline \multicolumn{5}{|l|}{ Work characteristics } \\
\hline \multicolumn{5}{|l|}{ Industry } \\
\hline Other, n (\%) & $8352(9.07)$ & $3433(8.60)$ & $4919(9.42)$ & 0.000 \\
\hline Construction industry, n (\%) & $27,304(29.64)$ & $5953(14.90)$ & $21,351(40.91)$ & 0.000 \\
\hline Service industry, n (\%) & $56,478(61.30)$ & $30,551(76.50)$ & $25,927(49.67)$ & 0.000 \\
\hline \multicolumn{5}{|l|}{ Migration traits } \\
\hline \multicolumn{5}{|l|}{ Migrated with children } \\
\hline Yes, n (\%) & $74,762(65.19)$ & $30,448(76.24)$ & $44,314(59.29)$ & \multirow[t]{2}{*}{0.000} \\
\hline No, n (\%) & $39,913(64.81)$ & $9489(23.76)$ & $30,424(40.71)$ & \\
\hline \multicolumn{5}{|l|}{ Migrated with couple } \\
\hline Yes, n (\%) & $84,230(73.45)$ & $34,200(85.63)$ & $50,030(66.94)$ & \multirow[t]{3}{*}{0.000} \\
\hline No, n (\%) & $30,445(26.55)$ & $5737(14.37))$ & $24,708(33.06)$ & \\
\hline $\mathrm{N}, \mathrm{n}(\%)$ & $114,675(100)$ & $39,937(34.83)$ & $74,738(65.17)$ & \\
\hline
\end{tabular}

SD Standard deviation

0.0053). In the migration trait, migrating couples $(\beta=-0.0961,95 \% \mathrm{CI}:-0.1653,-0.0269)$ was less likely to experience sub-health status.

The chronic disease model established that selfemployment increased the likelihood of suffering from chronic disease for rural migrants $(\beta=0.3401,95 \% \mathrm{CI}$ : $0.2792,0.4011)$. Being male $(\beta=0.1660,95 \%$ CI: 0.1071 , $0.2248)$, unmarried $(\beta=-0.3578 ; 95 \% \mathrm{CI}:-0.5029$, $-0.2128)$, low income $(\beta=-0.00003,95 \% \mathrm{CI}:-0.00004$, $-0.00001)$, and older rural migrants $(\beta=0.1119,95 \% \mathrm{CI}$ : $0.0916,0.1322)$ were more likely to suffer from chronic disease. By contrast, rural migrants who migrated with their children ( $\beta=-0.1220$, 95\% CI: $-0.1955,-0.0484)$ were less likely to suffer chronic disease.

\section{IV-LPM estimation}

IV-LPM was applied to correct the endogeneity of selfemployment. Table 4 showed LPM and IV-LPM estimations. The results indicated that self-employment still had a significantly negative effect on rural migrants' subhealth status and chronic disease even when we corrected 
Table 3 Logit regression models assessing the effect of self-employment on sub-health status and chronic disease

\begin{tabular}{|c|c|c|c|c|}
\hline & \multicolumn{2}{|c|}{ Sub-health status } & \multicolumn{2}{|c|}{ Chronic disease } \\
\hline & $\beta$ & $95 \% \mathrm{Cl}$ & $\beta$ & $95 \% \mathrm{Cl}$ \\
\hline \multicolumn{5}{|l|}{ Employment status } \\
\hline Self-employed & $0.0377^{*}$ & $(-0.0044-0.0798)$ & $0.3401^{* * *}$ & $(0.2792-0.4011)$ \\
\hline Wage-employed & Reference & & Reference & \\
\hline \multicolumn{5}{|l|}{ Gender } \\
\hline Male & $-0.1508^{* * *}$ & $(-0.1913--0.1103)$ & $0.1660^{* * *}$ & $(0.1071-0.2248)$ \\
\hline Female & Reference & & Reference & \\
\hline Age & $0.0265^{* * *}$ & $(0.0124-0.0405)$ & $0.1119^{* * *}$ & $(0.0916-0.1322)$ \\
\hline $\mathrm{Age}^{\wedge} 2$ & $0.0002^{* *}$ & $(0.00005-0.0004)$ & $-0.0004^{* * *}$ & $(-0.0007--0.0002)$ \\
\hline \multicolumn{5}{|l|}{ Education attainment } \\
\hline Primary school or below & Reference & & Reference & \\
\hline Junior high school & $-0.1764^{* * *}$ & $(-0.2271--0.1257)$ & $-0.3176^{* * *}$ & $(-0.3842--0.2510)$ \\
\hline Senior high school & $-0.1826^{* * *}$ & $(-0.2471--0.1181)$ & $-0.4113^{* * *}$ & $(-0.5038--0.3188)$ \\
\hline College or above & $-0.1708^{* * *}$ & $(-0.2545--0.0872)$ & $-0.7574^{* * *}$ & $(-0.9141--0.6007)$ \\
\hline \multicolumn{5}{|l|}{ Marital status } \\
\hline Married & $0.2514^{* * *}$ & $(0.1570-0.3458)$ & $-0.3578^{* * *}$ & $(-0.5029--0.2128)$ \\
\hline Unmarried & Reference & & Reference & \\
\hline Income (monthly) & $-0.00004^{* *}$ & $(-0.00005--0.00003)$ & $-0.00003^{* * *}$ & $(-0.00004--0.00001)$ \\
\hline \multicolumn{5}{|l|}{ Industry } \\
\hline Other & Reference & & Reference & \\
\hline Construction industry & $-0.0690^{*}$ & $(-0.1404-0.0024)$ & 0.0666 & $(-0.0361-0.1693)$ \\
\hline Service industry & $-0.0616^{*}$ & $(-0.1285-0.0053)$ & 0.0401 & $(-0.0537-0.1339)$ \\
\hline \multicolumn{5}{|l|}{ Migrated with children } \\
\hline Yes & 0.0101 & $(-0.0449-0.0651)$ & $-0.1220^{* * *}$ & $(-0.1955--0.0484)$ \\
\hline No & Reference & & Reference & \\
\hline \multicolumn{5}{|l|}{ Migrated with couple } \\
\hline Yes & $-0.0961^{* * *}$ & $(-0.1653--0.0269)$ & -0.0307 & $(-0.1327-0.0713)$ \\
\hline No & Reference & & Reference & \\
\hline Constant & $-2.8197^{* * *}$ & $(-3.0807--2.5588)$ & $-5.8291^{* * *}$ & $(-6.2506--5.4076)$ \\
\hline
\end{tabular}

$\beta$ Logit regression Coefficient, $\mathrm{Cl}$ Confidence interval

***significant at $1 \%,{ }^{* *}$ significant at $5 \%,{ }^{*}$ significant at $10 \%$

the potential endogeneity by using IV-LPM regression. Self-employed migrants increased the likelihood that their sub-health status was bad by $0.47 \%$ or $2.4 \%$ and chronic disease was bad by $1.99 \%$ or $2.77 \%$, depending on the models. After closely examining the estimates from LPM and IV-LPM models, we found that results of the former were smaller in sub-health status model $(0.47 \%$ compared with $2.4 \%$ ) and chronic disease model (1.99\% compared with $2.77 \%$ ), which were in accord with the reserve causality story.

In terms of sub-health status, the IV-LPM estimation revealed that male $(\beta=-0.0183,95 \% \mathrm{CI}:-0.0230$, $-0.0136)$ and unmarried $(\beta=0.0241,95 \%$ CI: 0.0138 , 0.0344 ) rural migrants were less likely to be in sub-health status, and those who migrated as a couple $(\beta=-0.0141$, 95\% CI: $-0.0226,-0.0056)$ had less possibility to be in sub-health status. In addition, income $(\beta=-4.32 \mathrm{E}-06$, 95\% CI: $-5.16 \mathrm{E}-06,-3.48 \mathrm{E}-06)$ and educational attainment (junior high school: $\beta=-0.0266,95 \% \mathrm{CI}:-0.0333$, -0.0200 ; senior high school: $\beta=-0.0252,95 \% \mathrm{CI}$ : $-0.0334,-0.0171$; college or above: $\beta=-0.0198,95 \%$ CI: $-0.0307,-0.0090)$ had a negative impact on the likelihood of suffering sub-health status.

In the chronic disease model, male migrants ( $\beta=0.0088,95 \%$ CI: $0.0056,0.0120)$ were more susceptible to chronic disease, but migrants with higher educational attainment (junior high school: $\beta=-0.0269$, 95\% CI: $-0.0314,-0.0223$; senior high school: $\beta=-0.0290,95 \%$ CI: $-0.0346,-0.0234$; college or above: $\beta=-0.0315,95 \%$ CI: $-0.0389,-0.0240)$ and income ( $\beta=-1.38 \mathrm{E}-06,95 \%$ CI: $-1.96 \mathrm{E}-06,-8.04 \mathrm{E}-07)$ had a lower likelihood of suffering from chronic disease. 
Table 4 Causal effect between self-employment and health status among rural migrants: LPM and IV-LPM regression models

\begin{tabular}{|c|c|c|c|c|}
\hline & \multicolumn{2}{|l|}{ Sub-health status } & \multicolumn{2}{|l|}{ Chronic disease } \\
\hline & LPM & IV-LPM & LPM & IV-LPM \\
\hline \multicolumn{5}{|l|}{ Employment status } \\
\hline Self-employed & $0.0047^{*}(-0.0004,0.0097)$ & $0.0240^{* *}(0.0047,0.0433)$ & $0.0199 * * *(0.0163,0.0235)$ & $0.0277^{* * *}(0.0144,0.0410)$ \\
\hline Wage-employed & Reference & & Reference & \\
\hline \multicolumn{5}{|l|}{ Gender } \\
\hline Male & $\begin{array}{l}-0.0179^{* * *}(-0.0226 \\
-0.0132)\end{array}$ & $\begin{array}{l}-0.0183^{* * *}(-0.0230 \\
-0.0136)\end{array}$ & $0.0090^{* * *}(0.0058,0.0121)$ & $0.0088^{* * *}(0.0056,0.0120)$ \\
\hline Female & Reference & & Reference & \\
\hline Age & $\begin{array}{l}-0.0037^{* * *}(-0.0056 \\
-0.0019)\end{array}$ & $\begin{array}{l}-0.0041^{* * *}(-0.0058 \\
-0.0023)\end{array}$ & $\begin{array}{l}-0.0063^{* * *}(-0.0078 \\
-0.0049)\end{array}$ & $\begin{array}{l}-0.0065^{* * *}(-0.0076 \\
-0.0053)\end{array}$ \\
\hline Age $^{\wedge} 2$ & $0.0001^{* * *}(0.0001,0.0001)$ & $0.0001^{* * *}(0.0001,0.0001)$ & $0.0001^{* * *}(0.0001,0.0002)$ & $0.0001^{* * *}(0.0001,0.0001639)$ \\
\hline \multicolumn{5}{|l|}{ Education attainment } \\
\hline Primary school or below & Reference & & Reference & \\
\hline Junior high school & $\begin{array}{l}-0.0275^{* * *}(-0.0350 \\
-0.0200)\end{array}$ & $\begin{array}{l}-0.0266^{* * *}(-0.0333 \\
-0.0200)\end{array}$ & $\begin{array}{l}-0.0272^{* * *}(-0.0330 \\
-0.0215)\end{array}$ & $\begin{array}{l}-0.0269^{* * *}(-0.0314 \\
-0.0223)\end{array}$ \\
\hline Senior high school & $\begin{array}{l}-0.0277^{* * *}(-0.0361 \\
-0.0193)\end{array}$ & $\begin{array}{l}-0.0252^{* * *}(-0.0334 \\
-0.0171)\end{array}$ & $\begin{array}{l}-0.0300^{* * * *}(-0.0362 \\
-0.0238)\end{array}$ & $\begin{array}{l}-0.0290^{* * *}(-0.0346 \\
-0.0234)\end{array}$ \\
\hline College or above & $\begin{array}{l}-0.0254^{* * *}(-0.0348 \\
-0.0161)\end{array}$ & $\begin{array}{l}-0.0198^{* * *}(-0.0307 \\
-0.0090)\end{array}$ & $\begin{array}{l}-0.0337^{* * *}(-0.0401 \\
-0.0273)\end{array}$ & $\begin{array}{l}-0.0315^{* * *}(-0.0389 \\
-0.0240)\end{array}$ \\
\hline \multicolumn{5}{|l|}{ Marital status } \\
\hline Married & $0.0256^{* * *}(0.0161,0.0352)$ & $0.0241^{* * *}(0.0138,0.0344)$ & $-0.0049(-0.0110,0.0012)$ & $-0.0055(-0.0126,0.0016)$ \\
\hline Unmarried & Reference & & Reference & \\
\hline Income (monthly) & $\begin{array}{l}-4.09 \mathrm{E}-06^{* * *}(-4.88 \mathrm{E}-06 \\
-3.31 \mathrm{E}-06)\end{array}$ & $\begin{array}{l}-4.32 \mathrm{E}-06^{* * *}(-5.16 \mathrm{E}-06 \\
-3.48 \mathrm{E}-06)\end{array}$ & $\begin{array}{l}-1.29 \mathrm{E}-06^{* * *}(-1.89 \mathrm{E}-06 \\
-6.93 \mathrm{E}-07)\end{array}$ & $\begin{array}{l}-1.38 \mathrm{E}-06^{* * *}(-1.96 \mathrm{E}-06 \\
-8.04 \mathrm{E}-07)\end{array}$ \\
\hline \multicolumn{5}{|l|}{ Industry } \\
\hline Other & Reference & & Reference & \\
\hline Construction industry & $-0.0078^{*}(-0.0167,0.0010)$ & $-0.0051(-0.0141,0.0039)$ & $0.0043(-0.0020,0.0106)$ & $0.0054^{*}(-0.0007,0.0116)$ \\
\hline Service industry & $-0.0069(-0.0154,0.0016)$ & $\begin{array}{l}-0.0103^{* *}(-0.0191 \\
-0.0016)\end{array}$ & $0.0031(-0.0030,0.0092)$ & $0.0017(-0.0042,0.0077)$ \\
\hline \multicolumn{5}{|l|}{ Migrated with children } \\
\hline Yes & $0.0013(-0.0060,0.0086)$ & $0.0009(-0.0059,0.0078)$ & $\begin{array}{l}-0.0101 * * *(-0.0155 \\
-0.0047)\end{array}$ & $\begin{array}{l}-0.0102^{* * *}(-0.0149 \\
-0.0056)\end{array}$ \\
\hline No & Reference & & Reference & \\
\hline \multicolumn{5}{|l|}{ Migrated with couple } \\
\hline Yes & $\begin{array}{l}-0.0121^{* * *}(-0.0208 \\
-0.0033)\end{array}$ & $\begin{array}{l}-0.0141^{* * *}(-0.0226 \\
-0.0056)\end{array}$ & $-0.0004(-0.0064,0.0055)$ & $-0.0012(-0.0071,0.0046)$ \\
\hline No & Reference & & Reference & \\
\hline Constant & $0.1478^{* * *}(0.1165,0.1790)$ & $0.1501^{* * *}(0.1200,0.1802)$ & $0.1121^{* * *}(0.0881,0.1360)$ & $0.1129 * * *(0.0925,0.1334)$ \\
\hline
\end{tabular}

***significant at $1 \%,{ }^{* *}$ significant at $5 \%,{ }^{*}$ significant at $10 \%$

Furthermore, rural migrants who migrated with their children ( $\beta=-0.0102,95 \%$ CI: $-0.0149,-0.0056)$ were less likely to suffer from chronic disease.

\section{Mechanism analysis}

Why does self-employment show a negative impact on the health status of rural migrants? This study claimed that social health insurance may serve as the potential mechanism linking self-employment behavior and rural migrants' health in China. That is, self-employment influenced rural migrants' health via the access to health services determined by the enrollment in social health insurance. To investigate the transmission channel, we explored the relationship between self-employment and social health insurance. Table 5 revealed that the selfemployed in urban destinations was less likely to participate in social health insurance $(\beta=-2.6891,95 \% \mathrm{CI}$ : $-2.7559,-2.6223)$. 
Table 5 Logit regression models assessing the relationship between self-employment and social health insurance

\begin{tabular}{|c|c|c|}
\hline & \multicolumn{2}{|c|}{ Social health insurance } \\
\hline & $\beta$ & $95 \% \mathrm{Cl}$ \\
\hline \multicolumn{3}{|l|}{ Employment status } \\
\hline Self-employed & $-2.6891^{* * *}$ & $(-2.7559,-2.6223)$ \\
\hline Wage-employed & Reference & \\
\hline \multicolumn{3}{|l|}{ Gender } \\
\hline Male & $-0.0505^{* *}$ & $(-0.0906,-0.0104)$ \\
\hline Female & Reference & \\
\hline Age & $0.1847^{* * *}$ & $(0.1682,0.2012)$ \\
\hline $\mathrm{Age}^{\wedge} 2$ & $-0.0024^{* * *}$ & $(-0.0026,-0.0021)$ \\
\hline \multicolumn{3}{|l|}{ Education attainment } \\
\hline Primary school or below & Reference & \\
\hline Junior high school & $0.7024^{* * *}$ & $(0.6303,0.7744)$ \\
\hline Senior high school & $1.3755^{* * *}$ & $(1.2976,1.4534)$ \\
\hline College or above & $2.3361^{* * *}$ & $(2.2518,2.4204)$ \\
\hline \multicolumn{3}{|l|}{ Marital status } \\
\hline Married & $0.4233^{* * *}$ & $(0.3482,0.4984)$ \\
\hline Unmarried & Reference & \\
\hline Income (monthly) & $0.0001^{* * *}$ & $(0.00008,0.00009)$ \\
\hline \multicolumn{3}{|l|}{ Industry } \\
\hline Other & Reference & \\
\hline Construction industry & $0.8963^{* * *}$ & $(0.8241,0.9685)$ \\
\hline Service industry & $0.1161^{* * *}$ & $(0.0436,0.1886)$ \\
\hline \multicolumn{3}{|l|}{ Migrated with children } \\
\hline Yes & -0.0228 & $(-0.0807,0.0350)$ \\
\hline No & Reference & \\
\hline \multicolumn{3}{|l|}{ Migrated with couple } \\
\hline Yes & $-0.3237^{* * *}$ & $(-0.3881,-0.2593)$ \\
\hline No & Reference & \\
\hline Constant & $-5.9795^{* * *}$ & $(-6.2675,-5.6916)$ \\
\hline
\end{tabular}

$\beta$ Logit regression Coefficient, $\mathrm{Cl}$ Confidence interval

${ }^{* * *}$ significant at $1 \%,{ }^{* *}$ significant at $5 \%,{ }^{*}$ significant at $10 \%$

\section{Discussion}

The estimations from the logit regression and IV-LPM estimation confirmed that the self-employed were more susceptible to suffer from sub-health status and chronic disease, an outcome that implied that self-employment activities are not conducive to good health. This finding was in line with that of Rietveld, Kippersluis, and Thurik [35] who revealed a negative effect of self-employment on health status. Several reasons explained the negative relationship between the self-employment and health status of rural migrants in China. First, self-employment was a "double-edged sword" [11] that endowed autonomy and independence, but was accompanied by considerable uncertainty and market fluctuations. In general, self-employed migrants in China encountered numerous difficulties in starting a business, such as the lack of access to financial services, the tediousness of gaining official approval from authorities, complex business registration process, and the multitude of tax items involved [43, 44]. Those migrants need to be selfdependent and take on extreme pressure to survive, a condition that would impair their physical and mental health [45]. Additionally, the self-employed usually undertook more excessive work load than their waged counterparts [11], and this circumstance would minimize their leisure time and reduce health-promotion activities [20, 46]. In addition, long working hours would break their work-life balance and cause them to suffer from more tension or anxiety, thereby possibly generating sub-health outcomes $[47,48]$. These disadvantages from self-employment might increase the risks of poor health status among rural migrants.

The result of mechanism analysis revealed that the self-employed were less likely to enroll in social health insurance, a situation which may lead to insufficient medical service if they become sick. Such a service would be detrimental to their health recovery. This result may be attributed to the unique public health insurance systems in China. In urban destinations, self-employed rural migrants were only eligible to participate in the project Urban Employee Basic Medical Insurance (UEBMI) [49]. The UEBMI for the wage-employed was jointly financed by employers and employees. By contrast, the selfemployed were required to pay the insurance premium for themselves, and the resulting costs accounted for $5-8 \%$ of the average monthly wage of local residents. This cost was a heavy burden for the self-employed migrants. Therefore, respondents had to give up the rights to participate in basic social health insurance. Without enrollment in the urban social health insurance system, self-employed rural migrants needed to shoulder the entire cost of health services on their own, a circumstance that forced them turn to informal and insufficient health services, such as unsupervised self-medication, medical advice from unlicensed private clinics, or simply endure minor illnesses without seeking any health services.

Self-employment might be linked to worse health outcomes, whereas the lack of health insurance among selfemployed migrants may hamper their access to formal health care, thereby inducing poorer health status and higher depression related to self-employment. This interesting finding diverged from the evidence from the US. A few studies on the relationship between self-employment and health status in the US revealed that self-employment does not impact the health status of the selfemployed, even if they lacked health insurance $[26,50]$. The potential explanation for this contradiction was that self-employed people in the US can access equal health 
care services through self-insurance. Consequently, selfemployment was merely negatively associated with having diabetes and hypertension, but was not significantly associated with negative mental health outcomes in the US context. In the Chinese counterpart, self-employed migrants remained vulnerable groups [51] and had limited ability to afford self-insurance using their own earning or savings. Thus, self-employed migrants in China were more likely to suffer from sub-health status and chronic disease in the absence of public health insurance.

\section{Limitations}

This study explored the causal effect of self-employment on the sub-health status and chronic disease of rural migrants. Unfortunately, we could not explore the long-term relationship between self-employment and sub-health status as well as chronic diseases for rural migrants because of the lack of longitudinal data. Although this work employed the IV-LPM estimation to correct the endogeneity of selfemployment, sub-health status and chronic disease may arise from self-employment in the long-term. Therefore, longitudinal data should be used to explore the effect in future studies. Additionally, due to the limitation of the dataset, we couldn't explore the effect of self-employment on hypertension and diabetes of rural migrants, respectively, which can be done in future research.

\section{Conclusion}

This study discussed the causal effect of self-employment on rural migrants' health in the context of China using the dataset from the NMPDMS-2017. After correcting the endogeneity, the results confirmed that the selfemployed were more likely to suffer sub-health status and chronic disease, and self-employment behavior exerted a harmful effect on rural migrants' health. Social health insurance may also serve as the transmission channel linking self-employment and rural migrants' health. That is, the self-employed were less prone to participate in urban health insurance programs, thereby inducing insufficient health services for maintaining health.

This conclusion offered implications. The government should play an important role in enhancing the entrepreneurial climate to enlarge the financial access and remove institutional barriers to the self-employment of rural migrants. Public health service should be provided equally for self-employed rural migrants, including expanding the coverage of urban social health insurance programs and improving the reimbursement levels.

\section{Appendix}

Table 6 Estimation of province self-employment rate and selfemployment: First stage

\begin{tabular}{|c|c|c|c|c|}
\hline & \multirow{2}{*}{\multicolumn{2}{|c|}{$\begin{array}{l}\text { Sub-health status } \\
\text { Self-employment }\end{array}$}} & \multirow{2}{*}{\multicolumn{2}{|c|}{$\begin{array}{l}\text { Chronic disease } \\
\text { Self-employment }\end{array}$}} \\
\hline & & & & \\
\hline & $\beta$ & $95 \% \mathrm{Cl}$ & $\beta$ & $95 \% \mathrm{Cl}$ \\
\hline $\begin{array}{l}\text { Self-employ- } \\
\text { ment rate }\end{array}$ & $1.0938^{* * *}$ & $(1.067,1.120)$ & $1.0932^{* * *}$ & $(1.067,1.120)$ \\
\hline \multicolumn{5}{|l|}{ Gender } \\
\hline Male & $0.0157^{* * *}$ & $(0.010,0.022)$ & $0.0150^{* * *}$ & $(0.009,0.021)$ \\
\hline Female & Reference & & Reference & \\
\hline Age & $0.0161^{* * *}$ & $(0.014,0.018)$ & $0.0156^{* * *}$ & $(0.014,0.018)$ \\
\hline Age $\wedge 2$ & $-0.0002^{* * *}$ & $\begin{array}{l}(-0.0002 \\
-0.0001)\end{array}$ & $-0.0002^{* * *}$ & $\begin{array}{l}(-0.0002 \\
-0.0001)\end{array}$ \\
\hline \multicolumn{5}{|c|}{ Education attainment } \\
\hline $\begin{array}{l}\text { Primary } \\
\text { school or } \\
\text { below }\end{array}$ & Reference & & Reference & \\
\hline $\begin{array}{l}\text { Junior high } \\
\text { school }\end{array}$ & $-0.0368^{* * *}$ & $\begin{array}{l}(-0.045 \\
-0.028)\end{array}$ & $-0.0368^{* * *}$ & $(-0.045,-0.029)$ \\
\hline $\begin{array}{l}\text { Senior high } \\
\text { school }\end{array}$ & $-0.1257^{* * *}$ & $\begin{array}{l}(-0.136 \\
-0.116)\end{array}$ & $-0.1251^{* * *}$ & $(-0.135,-0.115)$ \\
\hline $\begin{array}{l}\text { College or } \\
\text { above }\end{array}$ & $-0.2747^{* * *}$ & $\begin{array}{l}(-0.286 \\
-0.263)\end{array}$ & $-0.2748^{* * *}$ & $(-0.286,-0.263)$ \\
\hline \multicolumn{5}{|l|}{ Marital status } \\
\hline Married & $0.0958^{* * *}$ & $(0.083,0.109)$ & $0.0964^{* * *}$ & $(0.087,0.109)$ \\
\hline Unmarried & Reference & & Reference & \\
\hline $\begin{array}{l}\text { Income } \\
\text { (monthly) }\end{array}$ & $0.00002^{* * *}$ & $\begin{array}{l}(0.00001, \\
0.00002)\end{array}$ & $0.00002^{* * *}$ & $(0.00001,0.00002)$ \\
\hline \multicolumn{5}{|l|}{ Industry } \\
\hline Other & Reference & & Reference & \\
\hline $\begin{array}{l}\text { Construction } \\
\text { industry }\end{array}$ & $-0.1084^{* * *}$ & $\begin{array}{l}(-0.119, \\
-0.098)\end{array}$ & $-0.1124^{* * *}$ & $(-0.123,-0.102)$ \\
\hline $\begin{array}{l}\text { Service } \\
\text { industry }\end{array}$ & $0.1647^{* * *}$ & $(0.155,0.175)$ & $0.1620^{* * *}$ & $(0.152,0.172)$ \\
\hline \multicolumn{5}{|c|}{ Migrated with children } \\
\hline Yes & $0.0094^{* *}$ & $(0.001,0.018)$ & $0.0093^{* *}$ & $(0.0008,0.018)$ \\
\hline No & Reference & & Reference & \\
\hline \multicolumn{5}{|c|}{ Migrated with couple } \\
\hline Yes & $0.0904^{* * *}$ & $(0.080,0.101)$ & $0.0898^{* * *}$ & $(0.079,0.100)$ \\
\hline No & Reference & & Reference & \\
\hline Constant & $-0.4406^{* * *}$ & $\begin{array}{l}(-0.479 \\
-0.402)\end{array}$ & $-0.4300^{* * *}$ & $(-0.468,-0.392)$ \\
\hline $\begin{array}{l}\text { Under } \\
\text { identification } \\
\text { test (Anderson } \\
\text { canon. corr. LM } \\
\text { statistic) }\end{array}$ & $P$-value $=0.000$ & & $P$-value $=0.0$ & \\
\hline $\begin{array}{l}\text { Weak identi- } \\
\text { fication test } \\
\text { (Crag -Donald } \\
\text { Wald F statistic) }\end{array}$ & \multicolumn{2}{|l|}{ F statistic $=6477$} & \multicolumn{2}{|c|}{ F statistic $=6548.51$} \\
\hline
\end{tabular}

Note: 1. $\beta$ Logit regression Coefficient, $C /$ Confidence interval. $2 .{ }^{* * *}$ significant at $1 \%$, ${ }^{*}$ significant at $5 \%,{ }^{*}$ significant at $10 \%$ 


\section{Abbreviations}

NMPDMS-2017: The National Migrants Population Dynamic Monitoring Survey 2017; IV-LMP: Linear probability model with instrument variable.

\section{Acknowledgements}

Not applicable.

\section{Authors' contributions}

JZ took leadership and responsibility for the research activity planning and made substantial contributions to the conception and design of the Programme. QW worked on the statistical analysis of the data. ZW drafted the concept of the paper as well as participated in finalizing the manuscript. All authors read and approved the final manuscript.

\section{Funding}

This article is funded by the National Social Science Fund of China (Granted number 21BJY258 \& 18ZDA081), the National Natural Science Foundation of China(Granted number 72004080) and the Fundamental Research Funds for the Central Universities(Granted number 19JNQM16).

\section{Availability of data and materials}

The NMPDMS was open and available dataset from the Migrant Population Service Center of National Health Commission, the People's Republic of China (PRC). NMPDMS was however available from the Migrant Population Service Center of National Health Commission upon reasonable research request. NMPDMS could be requested from the website of Migrant Population Service Center: http://www.chinaldrk.org.cn/wjw/.

\section{Declarations}

\section{Ethics approval and consent to participate}

This study was a secondary analysis conducted according to data from the NMPDMS-2017 conducted by the National Health and Family Planning Commission of China. All those data were subject to multiple stages of reviews by experts to address the methodological, ethical, and legal issues related to data collection. Final approvals of all NMPDMS surveys were required from the Research Ethics Committee of the National Health and Family Planning Commission of China to ensure that the data collection complied with the ethical requirement according to the Statistics Act.

\section{Consent for publication}

Not applicable.

\section{Competing interests}

The authors declare that they have no competing interests.

Received: 23 August 2020 Accepted: 10 November 2021 Published online: 11 December 2021

\section{References}

1. Chan KW. Migration and development in China: trends, geography and current issues. Migr Dev. 2012;1(2):187-205.

2. Shen J, Xu W. Migration and development in China: introduction. China Rev. 2016;16(3):1-7.

3. Zheng Z, Lian P. Health vulnerability among temporary migrants in urban China; 2005.

4. Li S. The economic situation of rural migrant workers in China. China Perspect. 2010;2010(4):4

5. Li X, Stanton B, Chen X, et al. Health indicators and geographic mobility among young rural-to-urban migrants in China. World Health Popul. 2006;8(2):5

6. Luo H, Yang H, Xu X, et al. Relationship between occupational stress and job burnout among rural-to-urban migrant workers in Dongguan, China: a cross-sectional study. BMJ Open. 2016;6(8):e012597.

7. Mou J, Griffiths SM, Fong H, et al. Health of China's rural-urban migrants and their families: a review of literature from 2000 to 2012. Br Med Bull. 2013;106(1):19-43.
8. Cui Y, Nahm D, Tani M. Self-employment in China: are rural migrant workers and urban residents alike? In: Self-employment in China: Institute for the Study of Labor (IZA); 2013. Available from: https://citeseerx.ist.psu. edu/viewdoc/download?doi=10.1.1.303.2329\&rep=rep1\&type=pdf/.

9. Hundley G. Why and when are the self-employed more satisfied with their work? Ind Relat. 2001;40(2):293-316.

10. Taylor MP. Earnings, independence or unemployment: why become selfemployed? Oxf Bull Econ Stat. 1996;58(2):253-66.

11. Lewin-Epstein N, Yuchtman-Yaar E. Health risks of self-employment. Work Occup. 1991;18(3):291-312.

12. Hessels J, Rietveld CA, van der Zwan P. Self-employment and work-related stress: the mediating role of job control and job demand. J Bus Ventur. 2017;32(2):178-96.

13. Benz M, Frey BS. Being independent raises happiness at work. Swed Econ Policy Rev. 2004;11(2):95-134.

14. Blanchflower DG, Oswald AJ. What makes an entrepreneur? J Labor Econ. 1998;16(1):26-60

15. Goncalves J, Martins P S. The effect of self-employment on health: evidence from longitudinal social security data. IZA discussion papers, 2018.

16. Stephan U, Roesler U. Health of entrepreneurs versus employees in a national representative sample. J Occup Organ Psychol. 2010;83(3):717-38

17. Grant N, Wardle J, Steptoe A. The relationship between life satisfaction and health behavior: a cross-cultural analysis of young adults. Int J Behav Med. 2009;16(3):259-68.

18. Strine TW, Chapman DP, Balluz LS, et al. The associations between life satisfaction and health-related quality of life, chronic illness, and health behaviors among US community-dwelling adults. J Community Health. 2008;33(1):40-50.

19. Binder M, Coad A. An examination of the dynamics of well-being and life events using vector autoregressions. J Econ Behav Organ. 2010;76(2):352-71.

20. Taris TW, Geurts SAE, Schaufeli WB, et al. All day and all of the night: the relative contribution of two dimensions of workaholism to well-being in self-employed workers. Work Stress. 2008;22(2):153-65.

21. Nordenmark M, Vinberg S, Strandh M. Job control and demands, worklife balance and wellbeing among self-employed men and women in Europe. Vulnerable Groups Inclusion. 2012;3(1):18896.

22. Gilboa S, Shirom A, Fried Y, et al. A meta-analysis of work demand stressors and job performance: examining main and moderating effects. Pers Psychol. 2008;61(2):227-71.

23. Jamal M. Job stress, satisfaction, and mental health: an empirical examination of self-employed and non-self-employed Canadians. J Small Bus Manag. 1997;35(4):48.

24. Wills TA, Vaccaro D, McNamara G, et al. Escalated substance use: a longitudinal grouping analysis from early to middle adolescence. J Abnorm Psychol. 1996;105(2):166-80.

25. Siegrist J, Rödel A. Work stress and health risk behavior. Scand J Work Environ Health. 2006:473-81.

26. Yoon J, Bernell SL. The effect of self-employment on health, access to care, and health behavior. Health. 2013;5(12):2116-27.

27. Giandrea M D, Cahill KE, Quinn J F, et al. Self-Employment Transitions among Older American Workers with Career Jobs. 2008. Available from: https://citeseerx.ist.psu.edu/viewdoc/download?doi=10.1.1.217.4135\& rep=rep1\&type=pdf/.

28. Geurts SAE, Sonnentag S. Recovery as an explanatory mechanism in the relation between acute stress reactions and chronic health impairment. Scand J Work Environ Health. 2006;32(6):482-92.

29. DeVol R, Bedroussian A, Charuworn A, et al. An unhealthy America: the economic burden of chronic disease, vol. 326. Santa Monica: Milken Institute; 2007. p. 2010-60.

30. Yan YX, Liu YQ, Li M, et al. Development and evaluation of a questionnaire for measuring suboptimal health status in urban Chinese. J Epidemiol. 2009;19(6):333-41.

31. Yan YX, Dong J, Liu YQ, et al. Association of suboptimal health status and cardiovascular risk factors in urban Chinese workers. J Urban Health. 2012;89(2):329-38.

32. Zhongguancun Xinzhiyuan Health Management Institution. Blue book of health management: annual report on development of health 
management and health industry in China no.1 (2018). China: Central South University, Social Science Academic Press; 2018.

33. Tilov B, Semerdzhieva M, Bakova D, Tornyova B, Stoyanov D. Study of the relationship between aggression and chronic diseases (diabetes and hypertension). J Eval Clin Pract. 2016;22(3):421-4.

34. Le AT. Empirical studies of self-employment. J Econ Surv. 1999;13(4):381-416

35. Rietveld CA, van Kippersluis H, Thurik AR. Self-employment and health: barriers or benefits? Health Econ. 2015;24(10):1302-13.

36. Wong DFK, He X, Leung G, et al. Mental health of migrant workers in China: prevalence and correlates. Soc Psychiatry Psychiatr Epidemiol. 2008;43(6):483-9.

37. Giandrea MD, Cahill KE, Quinn JF. Self-employment transitions among older American workers with career jobs: Boston College Department of Economics; 2008.

38. Gorgievski MJ, Bakker AB, Schaufeli WB. Work engagement and workaholism: comparing the self-employed and salaried employees. J Posit Psychol. 2010;5(1):83-96.

39. Lan S, Gao X, Wang Q, Zhang Y. Public policy environment and entrepreneurial activities: evidence from China. China World Econ. 2018;26(3):88-108.

40. Zhou W. Regional deregulation and entrepreneurial growth in China's transition economy. Entrepreneurship Reg Dev. 2011;23(9-10):853-76.

41. Dawson C, Henley A, Latreille P. Individual motives for choosing selfemployment in the UK: does region matter? Reg Stud. 2014;48(5):804-22.

42. Alexandrova M. Entrepreneurship in a transition economy: the impact of environment on entrepreneurial orientation. Probl Perspect Manag. 2004;(2):140-8. Available from: http://citeseerx.ist.psu.edu/viewdoc/ download?doi=10.1.1.460.9952\&rep=rep1\&type $=$ pdf/.

43. Alon I, Yeheskel O, Lerner M, et al. Internationalization of Chinese entrepreneurial firms. Thunderbird Int Bus Rev. 2013;55(5):495-512.

44. Lu J, Tao Z. Determinants of entrepreneurial activities in China. J Bus Ventur. 2010;25(3):261-73.

45. Van der Hulst M. Long workhours and health. Scand J Work Environ Health. 2003;29(3):171-88.

46. van der Zwan P, Hessels J, Rietveld CA. Self-employment and satisfaction with life, work, and leisure. J Econ Psychol. 2018;64:73-88.

47. Lunau T, Bambra C, Eikemo TA, et al. A balancing act? Work-life balance, health and well-being in European welfare states. Eur J Public Health. 2014;24(3):422-7.

48. Leineweber C, Baltzer M, Magnusson Hanson LL, et al. Work-family conflict and health in Swedish working women and men: a 2-year prospective analysis (the SLOSH study). Eur J Public Health. 2013;23(4):710-6.

49. Qiu P, Yang Y, Zhang J, et al. Rural-to-urban migration and its implication for new cooperative medical scheme coverage and utilization in China. BMC Public Health. 2011;11(1):1-10.

50. Perry CW, Rosen HS. The self-employed are less likely to have health insurance than wage earners. So what? In: Public policy and the economics of entrepreneurship; 2003. p. 23.

51. Ning G, Qi W. Can self-employment activity contribute to ascension to urban citizenship? Evidence from rural-to-urban migrant workers in China. China Econ Rev. 2017;45:219-31.

\section{Publisher's Note}

Springer Nature remains neutral with regard to jurisdictional claims in published maps and institutional affiliations.

Ready to submit your research? Choose BMC and benefit from:

- fast, convenient online submission

- thorough peer review by experienced researchers in your field

- rapid publication on acceptance

- support for research data, including large and complex data types

- gold Open Access which fosters wider collaboration and increased citations

- maximum visibility for your research: over $100 \mathrm{M}$ website views per year

At BMC, research is always in progress.

Learn more biomedcentral.com/submissions 